\title{
NOG ENKELE OPMERKINGEN OVER HET WOORD KABAJAN.
}

\author{
DOOR
}

Prof. T. J. BEZEMER.

Aanleiding, om nog een enkele opmerking te maken over beteekenis en afleiding van het woord kabajan vond ik in de eerste plaats in de omstandigheid, dat Prof. Berg er blijkbaar niet mee bekend is geweest, dat vóór hem reeds door een ander de afleiding van Skr. bhaya, of liever van het tegenwoordige Jav. baja, gesteld is. (Afgescheiden van de vraag, of v. d. Tuuk inderdaad deze afleiding als de juiste heeft beschouwd). Men vindt deze meening in een werk, dat door zijn titel niet doet vermoeden, welk een rijken schat van ethnografische en economische gegevens het bevat, n.1.: Dr. J. H. F. Sollewijn Gelpke. Naar aanleiding van Staatsblad 1870, No. 110. Hij zegt daarin p. $14-16$ o.a. over den kěbajan: „In allen geval heeft hij $^{1}$ ) niets te zeggen, zoodra de Javaan thuis is. De eenige, die dan te bevelen heeft, is de „kěbajan”. Huis aan huis roept hij de lieden op tot den arbeid, bepaalt hunne beurten van dienstlevering en maant hen aan tot het betalen der landrenten. Hoewel van den kěpala afhankelijk, die hem aanstelt en ontslaat, zooals al de anderen, is hij meer dan één hunner de vertrouweling van den kleinen man, wiens verzoeken hij aan den kamitoewa overbrengt en tegen wien hij soms met den koeli één lijn trekt. Naar de tuinen ziet men hem de patjol's en naar de waterleidingen de koevoeten dragen, terwijl hij in tijden van drukke diensten, ,sěrangan" noemt het de Javaan, het eten van de woningen der dienstplichtigen haalt en naar de velden brengt.

„Evenals de kamitoewa behoort ook de kĕbajan in de oud-Javaansche desa te huis.

„Wezenlijk Javaansch ${ }^{2}$ ) is djogobojo. „Bojo” beteekent moeite;

1) D.i. de kamitoewa.

2) Als naam voor den "politiedienaar" der desa.

D1. 101. 
bezwaar, soesah, en djogobojo dus ,djogo soesah". Wat deze djogobojo nu doet moest oorspronkelijk de kěbajan verrichten. Het woord „kĕbajan" zelf is het transitief accidenteel passief van bojo en wil zeggen: „die met de soesah der desa is bezwaard", hetgeen overdrachtelijk hetzelfde kan beteekenen als ,kapetěngngan'”, ${ }^{1}$ ).

Opgemerkt moet worden, dat in elk geval de beteekenis, die Sollewijn Gelpke aan het woord geeft, etymologisch juister is dan die van Prof. Berg. Immers, bhaya en baja beteekenen: gevaar, niet gevaarlijk; de afleiding kabajan zou alleen: gevaarlijkheid, dat is dus: gevaar kunnen beteekenen, wanneer het stamwoord een adjectief was. Gevaarlijk zou moeten luiden: ambajani; en dit woord zou dan ook gebruikt moeten worden voor ,heerschers en priesters, personen die door hun positie in de familie en in de maatschappij of door hun wijding gezag hebben over anderen, daar grooter prestatievermogen uiting is van grooter magische kracht" (Berg in Bijdr. 85, p. 472).

De noot van Prof. Berg op p. 629 van Deel 90 dezer „Bijdragen” lost het bezwaar tegen zijn afleiding geenszins op. Hij zegt daar : ,dat men zich, wanneer men kabhayan van bhaya afgeleid acht, de adjectivische beteekenis: magisch-gevaarlijk moet voorstellen als ontstaan uit de substantivische beteekenis: magisch gevaar, die primair zou zijn". Vooreerst lijkt de substantivische beteekenis juist niet primair; en, al ware dit het geval, dan is het toch zeer vreemd, dat men eerst van een substantief een ander substantief zou gevormd hebben, dit daarna een adjectivische beteekenis gegeven hebben, om het vervolgens weer als substantief, n.l. als naam van een persoon, te gaan gebruiken.

Hoewel het onwaarschijnlijk is, dat werkelijk de afleiding van bhaya de juiste is, zoo lijkt het mij in elk geval hoogst annemelijk dat de Javaansche volksetymologie het woord kěbajan met baja in verband brengt, en dan in de beteekenis die Sollewijn Gelpke er aan geeft. En in deze beteekenis zou de naam ook zeer goed passen voor den kabajan op Bali, maar niet, zooals Berg zegt, in den zin van ,magischkrachtig", maar juist : aan (magisch-krachtige) gevaren blootgesteld.

De tweede gissing van Prof. Berg in Bijdr. 85 p. 477, 478 n.1. dat kabajan afgeleid zou zijn van het Javaansche grondwoord (bi) (*baj) lijkt mij op nog meer bezwaren te stuiten. Immers, het stamwoord $b a j$ is voor het Oud-Javaansch geheel hypothetisch, daar reeds in het Rāmāyaṇa de vorm $b i$ voorkomt, evenals anakbi, terwijl in het

1) Een andere naam voor djagabaja. 
Wirāțaparwwa zelfs een afleiding kānakbyan, vrouwenverblijf, gevonden wordt, een afleiding dus van $b i$, niet van baj. Trouwens, de groote moeilijkheid, dat een woord, dat „,,,vrouwelijkheid”, vrouwelijke aard", desnoods ook ,groep vrouwen” " beteekent, als naam voor een ambt, steeds door een man bekleed, in gebruik zou zijn gekomen, wordt door Berg erkend en allerminst opgelost.

In zijn artikel Kabajan in Deel 100 der Bijdragen verklaart Dr. Rassers, dat voor hem toch de afleiding van *baj de meest aannemelijke is, en hij tracht van een anderen dan den taalkundigen kant meer licht op het woord, of liever, op de ambtsdragers, die den titel kabajan hebben, te werpen.

Zooals bekend zijn voor Dr. Rassers kajon en kris de beide schijnwerpers, die met helderen glans de duisternis van de oud-Javaansche stamorganisatie verlichten, en bij dat licht beschouwt hij ook het vraagstuk van den kabajan. Hij zegt (p. 384 e.v.) : „De verschillende afleidingen die de etymologen ons aan de hand hebben gedaan, zullen wij pas naar een behoorlijken maatstaf kunnen beoordeelen, wanneer van den anderen kant ook de aard van de personen en zaken, die de Indonesiër met het woord kabajan benoemt, ons voldoende duidelijk zal zijn. Aan dit laatste nu ontbreekt nog zoo goed als alles; onderzoekingen in deze richting zijn nog nauwelijks ondernomen. Het is niet alleen dat wij, bij den tegenwoordigen stand onzer kennis, in al die personen en dingen moeilijk eenig gemeenschappelijk element kunnen ontdekken; ook van elk op zich zelf hebben wij slechts een zeer vage voorstelling. Van den functionaris die op Java en Bali als kabajan wordt aangeduid, heeft nog niemand ons een scherp beeld gegeven; hij schijnt zich wel in enkele opzichten van andere gezagdragers te onderscheiden, maar welke beteekenis wij daaraan moeten hechten, weten wij niet. Niemand zal er voorts aan twijfelen, dat de Soendaneezen in hun Uilespiegel Si Kabajan nog wel iets anders en iets meer zien dan een hoogst onfatsoenlijken grappenmaker of dan een jonggetrouwd man die bij zijn schoonouders inwoont en voor deze allerlei werk verricht, - maar wat het is dat hen in deze figuur zoo bovenmate boeit, is ons volkomen onbekend. De figuur van Nènèk Kebajan is al even geheimzinnig; mevrouw Coster's betoog dat zij het oude vrouwtje is in de maan, dat volgens de mythe zich bezighoudt met het spinnen van een draad naar de aarde, klinkt aannemelijk genoeg, maar afdoende zijn wij er niet mee geholpen; want terstond rijst de vraag, hoe de geheel andere rol die zij in de Maleische romans speelt, daarmee dan in overeenstemming is te brengen". 
Laten wij den Soendaneeschen Uilespiegel en Nènèk Kebajan een oogenblik rusten, dan dient gezegd, dat Rassers' uitspraak omtrent den kabajan op Java en Bali verwondering wekt. Dat wij van hem slechts een ,vage voorstelling” zouden hebben, dat ,nog niemand ons een scherp beeld gegeven heeft" van dezen functionaris lijkt zeer overdreven. In de beschrijving van Dr. Sollewijn Gelpke, in het begin van dit artikel aangehaald, zit niets vaags, is alles even concreet. Ditzelfde kan gezegd worden van een oudere beschrijving, n.l. door den Directeur van de cultures in 1864: ,de kebajan, de persoon, die de bevelen van het dessahoofd aan den kleinen man overbrengt en de reclames van de bevolking aan het dessahoofd kenbaar maakt. Hij is dus een tusschenpersoon tusschen het dessahoofd en de bevolking. Gewoonlijk designeert het dessahoofd voor deze betrekking niet zijn zoon, omdat hij zeer goed begrijpt, dat de kebajan, vermits hij een overbrenger van soms zeer lastige en zeer strenge bevelen moet zijn, zelden bij de bevolking zich bemind kan maken, iets dat invloed op de keuze der bevolking voor zijn eventuëlen opvolger kan hebben. Bij voorkeur kiest hij voor deze betrekking den meest invloedrijken onder den kleinen man, zoo namelijk deze daartoe genegen is" ${ }^{1}$ ). Veel geheimzinnigs is er in deze beschrijving stellig niet.

Vergelijkt men deze gegevens met datgene, wat volgens Dr. Rassers de figuur van den kabajan ,,iets scherper zou omlijnen" ${ }^{2}$ ) dan is het m.i. duidelijk, dat dit alléén het geval kan zijn voor hem, die volledig met de conclusies van Rassers in zịn artikel „On the Javanese kris" kan instemmen. Maar zelfs voor diengene moeten Dr. Rassers' argumenten toch zeer onvoldoende genoemd worden. Uit het feit, dat in zéér enkele dèsa's een bruidegom, die zich in een dier dèsa's komt vestigen, voor de blandong's een beitel en een bijl, voor den kabajan een vierkant stuk wit goed of een broek van mori moet meebrengen, komt hij tot de ver strekkende conclusie dat, gegeven een vroegere dubbel-unilaterale maatschappijinrichting op Java, de beitel en de bijl als "mannelijke” voorwerpen gaan naar hen die ,de samenleving in haar vaderzijdige groepeering vertegenwoordigen; het ,vrouwelijke” waarde-voorwerp, het weefsel of het kleedingstuk, gaat naar den kabajan, omtrent wien wij dus thans kunnen concludeeren, dat hij een functicnaris is uit de oude matrilineale groe-

1) Eindrésumé van het onderzoek naar de rechten der Inlandsche bevolking op den grond op Java en Madoera. D1. III p. 186.

2) O.c. p. 386 . 
peering $\left.{ }^{1}\right)$. Wij mogen dit nog sterker uitdrukken: het gewichtige werk, dat wij hem hier zien verrichten ${ }^{2}$ ), toont ten duidelijkste aan, dat de kabajan, hoe ook thans zijn positie moge zijn, eenmaal op Java representaticf moet zijn geweest voor het moederzijdig aspect der samenleving" ${ }^{3}$ ).

Men zal niet kunnen ontkennen, dat deze uitspraak wel zeer apodictisch klinkt, als men in aanmerking neemt, dat zij feitelijk geheel gebaseerd is op een gewoonte, slechts vermeld van welgeteld twee dèsa's: Pekiringan (Banjoemas) en één ongenoemde in de afd. Poerbalingga. Rassers noemt dit gebruik: „blijkbaar zeer oud” (p. 387). Op welken grond? Met evenveel recht zou men het een zeer recent listigheidje van den kabajan in die dorpen kunnen noemen, om, als de blandongs wat krijgen, ook wat in de wacht te sleepen ${ }^{4}$ ). En wat betreft het geschenk voor de blandiongs, die ,de samenleving in haar vaderzijdige groepeering" zouden vertegenwoordigen, hier zou men dan toch in elk geval wel een kris mogen verwachten. Maar neen, eigenlijk niet eens een wapen, want beitel en bijl kunnen moeilijk zoo genoemd worden. En mori is Europeesch katoen!

Ook hetgeen Dr. Rassers verder op p. 390 over den kabajan zegt, kan moeilijk als bewijs voor diens representatieve functie voor het moederzijdige aspect der samenleving worden opgevat. De grond op Java een ,vrouwelijk” goed? Zou men dan ook niet een godin van den grond mogen verwachten? En is er eenige aanwijzing, dat de

1) Cursiveering van mij.

2) Welk gewichtig werk? Het ontvangen van een stuk weefsel of een broek?

3) O.c. p. 389 en 390.

4) Hoe voorzichtig men zijn moet met een of andere gewoonte op Java dadelijk als „oude adat" te verklaren is met tal van voorbeelden te bewijzen. Een treffend staaltje is het volgende. In verschillende streken van de residentie Bantam waren de huizen der Inheemsche bevolking omstreeks het einde der $19 \mathrm{de}$ en het begin der 20 ste eeuw zeer nauw op elkaar gebouwd, zoodat er van erven geen sprake was, en de dorpen meer het karakter droegen van één groot huis met een aantal gezinskamers. Op het eerste gezicht zou er aanleiding zijn dit verschijnsel als een zéér oude adat te verklaren. Niets is echter minder waar, daar die gewoonte toen nauwelijks een halve eeuw oud was. In Bantam had men n.l. in een aantal streken geen brinkdorpen als op Midden-Java en elders, maar bouwhoeven, te midden van elks bouwveld gelegen. Tot in 1845 resident Buyn samenwoning der bevolking gelastte. In deze nieuwe dorpen waren de woningen door voldoende tusschenruimten gescheiden, maar door vermeerdering der bevolking werden deze tusschenruimten allengs volgebouwd. En zóó snel vormde zich een nieuwe adat, dat ook nieuwe dorpen het karakter van een dorpsstraat van huizen zonder erven kregen. Sedert 1896 streefde het Bestuur weer naar verplaatsing der opeengehoopte woningen, zoodat ze minstens 3 Rijnl. roeden van elkaar staan. Van de vroegere woonwijze op bouwhoeven getuigen nog groepen manggaboomen te midden der bouwvelden. 
danhjang dèsa als godin wordt opgevat? Is de tjakal bakal dèsa niet de geest van den eersten ontginner van de dèsa? Op diezelfde bladzij wordt de kabajan de ,heer van den grond” genoemd. Als men op Java van een ,heer van den grond" wil spreken, dan is dat niemand anders dan de loerah. Leerzaam in dit opzicht zijn weder de belangrijke mededeelingen van een deskundige als Dr. Sollewijn Gelpke in het bovengenoemde werk; ik haal er slechts uit aan: „Over dien grond $^{1}$ ) was het desahoofd heer en meester. Zoo lang hij het goed vond, bleef men de sawah's, die men onder den ploeg had, bewerken. Wie nieuwe rijstvelden wilde maken, 't zij op de tegal's of op den woesten grond, vroeg hem verlof en verkreeg tevens drie of meer jaren vrijstelling van leveringen, naarmate afgesproken was" ${ }^{2}$ ).

„Het loon voor zijn werk (n.l. van den kabajan) is, zooals dat bij den "heer van den grond" te verwachten is, n.l. de belastingvrije beschikking over een veld" zegt Rassers op p. 390. Maar het zal hem toch niet onbekend zijn, dat, voorzoover ambtsvelden worden toegekend, alle leden van het dèsabestuur op deze wijze beloond worden, in de eerste plaats het dorpshoofd.

Wat Dr. Rassers, aan de hand van verschillende schrijvers, over de functie van den kabajan op Bali meedeelt, geeft m.i. al evenmin aanleiding tot de stellige uitspraak, dat men van deze gegevens ,op zich zelf beschouwd, niet kan zeggen dat zij ons een heldere voorstelling geven van de positie en de beteekenis van den kabajan" (p. 393). In geen geval geven ze den onbevangen onderzoeker aanleiding, hem, in tegenstelling met de andere leden van het dagelijksch bestuur der dèsa, te beschouwen als ,den aardschen verschijningsvorm en bode van de vrouwelijke voorouder, de Moeder-godin van het Balineesche volk" (p. 397). Deze conclusie is alléén mogelijk (en dan nog onder veel voorbehoud) als men instemt met Rassers' meening, dat ,de balé agoeng is de oude tempel der totale gemeenschap, in haar matrilineale groepeering; in wezen is dit gebouw volkomen gelijk te stellen met de kobongan van het Javaansche huis; de Balinees heeft in de daar gehouden bijeenkomsten zitting krachtens zijn moederzijdigen totem" (p. 390-391).

Ter adstructie van deze min of meer revolutionnaire stelling, wijst Rassers vooral op het feit, dat voor het lidmaatschap van de desavereeniging verplicht is, dat de man gehuwd is, en er een band van

1) n.1. van de dèsa.

2) O.c. p. 7 . 
hem met den grond moet zijn. „Maar men mag dit niet zóó opvatten, dat deze twee voorwaarden onafhankelijk van elkaar zouden zijn; de waarheid is, dat iemand, doordat hij in het huwelijk treedt, automatisch een aandeel krijgt in de dorpsgronden en tevens lid (of candidaat-lid) wordt van de desavereeniging met alle daaraan verbonden rechten en verplichtingen. Blijkbaar is op Bali de grond nog altijd een ,vrourvelijk" goed, dat de man in feite door zijn hurwelijk verwerf $\left.{ }^{1}\right)$, tegelijk krijgt hij dan medezeggenschap in het inwendig bestuur zijner gemeenschap. Sterft iemands vrouw, dan verliest hij terstond zijn grond, en hij houdt op lid te zijn van de dorpsvereeniging; aan deze capitis diminutio ontkomt hij alleen wanneer hij een reeds volwassen ongehuwde dochter heeft, of zijn moeder of een andere vrouw bij hem inwoont, die bij feesten voor het inleveren der offers kan zorgen. Wordt daarentegen een vrouw weduwe, dan is het mogelijk, dat zij haar dorpsgrondenaandeel behoudt" ${ }^{2}$ ).

Op het eerste gezicht schijnen deze bepalingen omtrent het lidmaatschap der desa-vereeniging grooten steun te geven aan Dr. Rassers' opvattingen. Maar de verklaring die Liefrinck geeft, lijkt niet slechts veel rationalistischer maar ook rationeeler. Hij zegt: „Komt de vrouw te sterven, dan blijft de desaman lid van de vereeniging, bijaldien hij eene reeds volwassen ongehuwde dochter, zijne moeder of eene andere vrouw bij zich in huis heeft wonen.

„Deze kan dan op het huis passen, als de man er op uit gaat om aan het onderhoud der wegen of het herstel der tempels deel te nemen; zij zorgt dat hij zoo noodig leeftocht meekrijgt, of als hij t' huis komt, het maal toebereid vindt, en past op de minderjarige kinderen, die nog in huis mochten zijn. Mist echter de weduwnaar de hulp eener vrouw en denkt hij er niet aan spoedig weer in het huwelijk te treden dan kan hij het moeilijk schikken om lid van de desavereeniging te blijven, want zoovele dagen worden daardoor geheel in beslag genomen, soms ook gansche nachten bij de feestelijke gelegenheden in de tempels.

„Hij moet dus besluiten om voor het lidmaatschap te bedanken ${ }^{3}$ ), en zoo daaraan het gebruik van een gedeelte van den desagrond verbonden was, dan moet hij daarvan ook afstand doen, tenzij er geen bezwaren tegen bestaan, dat hem het genot van dien grond gelaten

1) Cursiveering van mij.

2) O.c. p. 396 .

3) Cursiveering van mij. 
wordt tegen betaling van eene zekere huursom ten voordeele der desakas $\left.^{1}\right)$.

Ook Prof. Korn heeft een geheel afwijkende opvatting. „Dorpsgenooten zijn alleen diegenen, die ten volle geschikt geacht worden aan de zorg voor de gebiedsreinheid deel te kunnen nemen. Twee vereischten treden daarbij op den voorgrond, ten eerste: men moet gehuwd zijn, ten tweede: er moet een band bestaan tusschen den grond en het nieuwe lid. Het eerste vereischte berust op de leer, dat de mensch, door deel te gaan nemen aan de voortplanting, de voortbrengingsfunctie van den grond voortzet, aangezien alles uit den bodem voortkomt.

„De band met den grond kan ten aanzien van een bepaald stuk grond of bepaalde stukken grond zijn vereischt en dan heeft men den door Liefrinck bedoelden toestand van een dorp met een vast aantal kerndorpers, doch die band kan ook gelegd worden door toewijzing van een aandeel in reeds ontgonnen desagrond (Tenganan Pagringsingan), danwel door ontginning van een nieuw dorpsgrondenaandeel door het nieuwe lid (Kintamani). Het ledental is in deze beide gevallen voor uitbreiding vatbaar" ${ }^{2}$ ).

Uit het bovenstaande blijkt m.i. genoegzaam, dat het niet aangaat, van den grond op Bali te spreken als van een ,,vrouwelijk” goed, dat de man zou verwerven door zijn huwelijk. Evenals op Midden-Java, waar het ook wel voorkomt, dat een gogol, wiens vrouw gestorven is, zijn aandeel verliest, tot hij weer hertrouwt, heerscht op Bali de opvatting, dat alleen een gehuwd man een volwaardig lid der gemeenschap is.

Doch zelfs wanneer men met Dr. Rassers aanneemt, dat de balé agoeng is ,de oude tempel der totale gemeenschap in haar matrilineale groepeering", dan blijkt uit de opgesomde functies van den kabajan in geenen deele, dat juist hij onder al de "dèsa-bestuurders” in het bijzonder met deze ,groepeering" iets uitstaande heeft of gehad heeft. Integendeel, wanneer de grond op Bali nog als een „,vrouwelijk" goed wordt gevoeld, dan is het hoogst merkwaardig, dat niet de kabajan, maar de pasēk uitdrukkelijk door Korn de ,grondvoogd" genoemd wordt ${ }^{3}$ ).

Ook het ,extra-bewijs” voor Dr. Rassers' stelling, dat de kabajan zou zijn ,de aardsche verschijningsvorm van de vrouwelijke voor-

1) Cursiveering van mij.

$\left.{ }^{2}\right)$ Dr. V. E. Korn. Het Adatrecht van Bali, p. 180-181.

3) Korn. Adatrecht, p. 543. 
ouder, de Moeder-godin van het Balineesche volk" n.l. de gewijde voorschriften omtrent de kabajan-verheffing in den tempel te Bangkah, kan m.i. niet als zoodanig aanvaard worden. „Deze (kabajan) moet dan met zijn vrouw voor den tijd van vier jaren de patapan betrekken, d.i. de plaats waar de gewijde dorpsbezittingen worden bewaard. Man en vrouw mogen gedurende al dien tijd geen gemeenschap met elkaar hebben; de kabajan slaapt n.l. met de rijst; ,hij wordt één met Dēwri Sri" $\left.{ }^{1}\right)$. De cursieve woorden zijn Dr. Rassers' parafrase van de voorafgaande mededeeling van Korn. Dr. Korn evenwel zegt: „de man slaapt met de rijst, d.i. met de godin Sri, opgetast in de rijstschuur, dus in de open ruimte onder de djineng, de vrouw slaapt onder de godheid (Siwa, bestaande uit bovenbedoelde magische voorwerpen)" ${ }^{2}$ ).

Hij wordt dus niet één met Dēwi Sri (immers, hij slaapt met haar!) evenmin als de vrouw één wordt met Siwa.

Tenslotte nog een opmerking over hetgeen Dr. Rassers noemt „Een niet minder belangrijke reste van het dubbele stelsel” in de merkwaardige dèsa Tenganan-Pagringsingan, n.l. de opvoeding van jongens en meisjes in de jongelings- en maagdenvereenigingen.

„Men kan vrijwel zonder voorbehoud zeggen, dat de jongens worden ingewijd in het patrilineale verband, terwijl de meisjes deel gaan uitmaken van de matrilineale groepeering".

„De beteekenis van dit geheele instituut blijkt nu hieruit, dat er voor de kinderen geen vrije keus bestaat, bij welke vereeniging zij zich zullen aansluiten; de jongens moeten zich aansluiten bij de jongemannenvereeniging tot welke hun vader behoorde, de meisjes worden lid van de maagdenvereeniging van welke ook hun moeder lid was" (p. 395).

Deze opvattingen lijken vreemd. Immers, naar een dubbel unilineaal stelsel gerekend behooren in de mannelijke afstammingslijn toch zoowel mannen als vrouwen, en omgekeerd, in de vrouwelijke afstammingslijn zoowel vrouwen als mannen? Bovendien doorbreken juist dergelijke algemeene jongelings- of maagdenvereenigingen de banden van het genealogische systeem. Maar wat de genoemde Balische dèsa aangaat is er meer: Korn zegt: „Tusschen de drie jongelingen vereenigingen.... en de standen in de desa bestaat nu een zeker verband, doordat de eerste vereeniging omvat de jongeluii van de sangijang en de pradjoerit, pandé en bandèsa, de tweede die

1) Rassers, p. 397.

2) Korn, Adatrecht p. 197. 
der embak boeloeh en pasek en de derde die van de batoegoeling en idjeng" ${ }^{1}$ ).

Hoe zou het voor de jongens dan mogelijk zijn, een andere vereeniging dan die van hun vader te kiezen? Nog afgescheiden van het dood-natuurlijke in een kleine dèsa dat men niet bij een andere zal gaan.

Op grond van de voorafgaande opmerkingen geloof ik te mogen concludeeren, dat de beschouwingen van Dr. Rassers geenszins geschikt zijn, om de afleiding van het woord kabajan van een oudJavaansch ${ }^{*} b a j$ aannemelijker te maken.

Te minder is er reden voor de waarschijnlijkheid van deze afleiding, daar er een andere geopperd is, die m.i. op ongedwongen wijze recht doet weervaren aan alles wat we van den kabajan weten. Het is die van Dr. Walther Aichele, die het woord afgeleid acht van Mal. baja $=$ Jav. wajah $=S k r$. wajas, en het in vorm en beteekenis gelijk stelt met Jav. ketoezwan. De oorspronkelijke beteekenis zou dus geweest zijn oud, zeer oud, oudste.

En onafhankelijk van Dr. Aichele zijn ook de heer W. J. de Wilde en Prof. Dr. J. Gonda tot deze etymologie van kabajan gekomen, terwijl ook Prof. Berg, ondanks alle bezwaren die hij tegen het betoog van Dr. Aichele ontwikkelt, niet wil beweren, dat Dr. Aichele's opvatting onhoudbaar is, doch alleen meent aangetoond te hebben, dat vooralsnog het bewijs voor de juistheid daarvan volstrekt niet geleverd is, en toegeeft, dat, wat ook de oorsprong van het woord moge zijn, het in het Oud-Javaansch onder meer ook „oud” kan hebben beteekend ${ }^{3}$ ).

Ook zonder Aichele's opvatting van een excessief aan te nemen kan men tot de beteekenis van oudste komen en wel door hetgeen R. A. Kern heeft aangevoerd ${ }^{2}$ ). Volgens hem zou het praefix $k a$ ook dienen om één of meer uit een veelheid aan te wijzen, één of meer exemplaren van een soort, één of meer individuen uit de groep waaruit zij getild worden.

Brengen wij dit nu in verband met enkele gegevens uit Korn's Adatrecht van Bali, dan schijnen ook deze de opvatting van Dr. Aichele te bevestigen.

p. 185 „De krama désa en het désabestuur zijn in den regel

1) Korn. Tenganan-Pagringsingan p. 51.

2) Bijdr. D1. 97, p. 428.

3) $\mathrm{Zie}$ voor een en ander Prof. Berg's artikel: Nog een paar opmerkingen over het woord „Kabayan” in Deel 90 der „Bijdragen”. 
verdeeld in twee helften, die men aanduidt als wajan en njoman (oudere en jongere)”, id. „Liefrinck heeft reeds opgemerkt, dat een zeker aantal der oudste leden in sommige desa's een „zoogenaamd bestuur" vormen, rama désa of prewajah geheeten, met welken laatsten term ook wel alleen de oudste twee leden aangeduid worden”.

p. 194 ,De kabajan vertegenwoordigt en eert Batara Angertā Boemi of I. Déwa Trang Boemi, ter eere van welke godheid een tienjaarlijksch feest gegeven wordt. Zwart is zijn kleur, hij zit als oudste (wajah) en met het gelaat naar het zuiden".

p. 464. Het eerste en vijfde ${ }^{1}$ ) kind hebben voor den naam staan wajahan of wajan, het tweede en zesde nengah enz.".

Er blijkt hieruit, dat op Bali niet alleen wajah maar ook wajan (uit wajahan) voor oudere, oudste gebruikt wordt. Wanneer we nu mogen aannemen, dat een oudere vorm van het woord kareajan is geweest, dan ligt de beteekenis voor de hand: één uit de groep der oudsten; inderdaad een volkomen passende benaming voor den functionaris zoowel op Java als op Bali ${ }^{2}$ ). Zoo is het woord volkomen gelijkwaardig met het Mal. ketoea, het Jav. kamitoewa. En evenmin als de tegenwoordige kamitoewa in de Javaansche desa de oudste behoeft te zijn, is dat noodig voor den kabajan daar of op Bali.

Indien inderdaad de afleiding van wajan heeft plaats gehad, wordt bovendien ook gereedelijk de verklaring gevonden van het op Bali naast kabajan zoo vaak voorkomende koebajan: ke of ka vóór een stamwoord met $w$ beginnende wordt veelal koe.

Dat de naam oudste of oudere ook passend is voor Nènèk Kebajan is duidelijk. Mevr. Dr. M. Coster-Wijsman zegt in haar proefschrift: Uilespiegelverhalen in Indonesië” op p. 22 „Daar nu kebajan in het O.-Jav. ook de beteekenis ,oud" heeft lijkt het mij voor de hand liggend, dat dit ook in het oud-Maleis zoo zal zijn geweest, zoodat de oorspronkelijke beteekenis van nènèk kebajan is: de Oude Vrouw".

Zelfs het Lampongsche kebajan zou met baja in verband gebracht kunnen worden, maar dan in den zin van: op een (bepaalden) leeftijd gekomen. Maar voor dit woord blijft altijd de mogelijkheid van afleiding van baj bestaan daar dit grondwoord nog in het MiddenMaleisch voorkomt in de beteekenis van ,echtgenoote, moeder, moederdier".

1) Blijkbaar begint men na het 4de kind als het ware weer opnieuw te tellen.

2) Kan men niet meegaan met de verklaring van Kern, dan zou nog te denken zijn aan de rangschikkende beteekenis van het praefix $k a$, zoowel in het Javaansch als in het Maleisch. 
Tenslotte, wat den Soendaaschen Si Kabajan betreft, daarover is door Dr. Berg en Mevrouw Coster-Wijsman reeds het noodige gezegd. In het bijzonder acht ik het juist, dat men den inhoud der verhalen, waarvan hij hoofdpersoon is, voor de vaststelling van de beteekenis van zijn naam kan uitschakelen. Als parallel kan gewezen worden op Uilenspiegel, waarvan men den inhoud der verhalen als verklaring voor zijn naam zou willen gebruiken, indien het niet vaststond, dat een nar van dien naam omstreeks 1350 te Mölln in Sleeswijk is gestorven, terwijl uit de tallooze verhalen omtrent streken, op zijn rekening gesteld, tegen het einde der $15 \mathrm{de}$ of het begin van de 16de eeuw het Duitsche volksboek over hem ontstaan is.

Van Si Kabajan zegt Dr. Rassers (p. 385) ,maar wat het is dat hen" (d.z. de Soendaneezen), in deze figuur zoo bovenmate boeit, is ons volkomen onbekend". Is dit zoo, dan moet deze vraag door de Soendaneezen beantwoord worden, niet door bespiegelingen omtrent de beteekenis van den naam van den held. Ongetwijfeld zal het antwoord van geen enkelen Soendanees luiden: „Wij zien in hem den middelaar en bode van den Schepper der wereld, hij vertegenwoordigt de totaliteit der samenleving met al haar — opbouwende èn storende - krachten; hij is cultuurheros en trickster en wel dit alles in matrilinealen zin, hij is wat zijn naam aanduidt: kabajan"1). En of dergelijke gedachten misschien leven in het onderbewustzijn der Soendaneezen - ook dat mag betwijfeld worden.

1) Rassers o.c. p. 402 . 